\title{
Ethnic variation in the annual rates of adult inflammatory bowel disease in hospitalized patients in Vancouver, British Columbia
}

\author{
Birinder K Mangat MD ${ }^{1}$, Chad Evaschesen $M D^{1}$, Tim Lee $\mathrm{PhD}^{2}$, \\ Eric M Yoshida MD FRCPC ${ }^{1}$, Baljinder Salh MB FRCPC FRCP(UK) ${ }^{1}$
}

\begin{abstract}
BK Mangat, C Evaschesen, T Lee, EM Yoshida, B Salh. Ethnic variation in the annual rates of adult inflammatory bowel disease in hospitalized patients in Vancouver, British Columbia. Can J Gastroenterol 2011;25(2):73-77.
\end{abstract}

BACKGROUND: There is currently little available information regarding the impact of ethnicity on the clinical features of inflammatory bowel disease (IBD). Migrating populations and changing demographics in Vancouver, British Columbia (BC) provide a unique opportunity to examine the role of ethnicity in the prevalence, expression and complications of IBD.

OBJECTIVES: To determine the demographics of IBD and its subtypes leading to hospitalization in the adult population of BC.

METHODS: A one-year retrospective study was performed for all patients who presented acutely with IBD to Vancouver General Hospital from January 1, 2006 to December 31, 2006. Data regarding sex, age, ethnicity, IBD type and extent of disease, complications and management strategies were collected. Clinical data were confirmed by pathology and radiology reports.

RESULTS: There were 186 cases of IBD comprising Crohn's disease (CD) $56 \%$, ulcerative colitis (UC) $43 \%$ and indeterminate colitis (1\%) $1 \%$. The annual rate of IBD cases warranting hospitalization in Caucasians was 12.9 per 100,000 persons ( 7.9 per 100,000 persons for CD and 5.0 per 100,000 persons for UC). This was in contrast to the annual rate of IBD in South Asians at 7.7 per 100,000 persons ( 1.0 per 100,000 persons for CD and 6.8 per 100,000 persons for UC) and in Pacific Asians at 2.1 per 100,000 persons ( 1.3 per 100,000 persons for CD, 0.8 per 100,000 persons for UC). The male to female ratio was higher in South Asians and Pacific Asians than in Caucasians. The extent of disease was significantly different across racial groups, as was the rate of complications.

CONCLUSIONS: These early results suggest that there are ethnic disparities in the annual rates of IBD warranting hospitalization in the adult population of $\mathrm{BC}$. There was a significantly higher rate of $\mathrm{CD}$ in the Caucasian population than in South Asian and Pacific Asian populations. The South Asian population had a higher rate of UC, with an increased rate of complications and male predominance. Interestingly, the rate of $\mathrm{CD}$ and UC was lowest in the Pacific Asian population. These racial differences - which were statistically significant - suggest a role for ethnodiversity and environmental changes in the prevalence of IBD in Vancouver.

Key Words: Crohn's disease; Ethnicity; Hospitalization; IBD; UC

\author{
La variation des taux annuels de maladies \\ inflammatoires de l'intestin chez les adultes \\ hospitalisés de Vancouver, en Colombie-Britannique, \\ selon l'ethnie
}

HISTORIQUE : On possède peu d'information sur les répercussions de l'ethnie sur les caractéristiques cliniques des maladies inflammatoires de l'intestin (MII). La migration des populations et l'évolution des caractéristiques démographiques à Vancouver, en Colombie-Britannique (C.-B.), fournissent une occasion unique d'examiner le rôle de l'ethnie dans la prévalence, l'expression et les complications des MII.

OBJECTIFS : Déterminer la démographie des MII et des sous-types de la maladie entraînant une hospitalisation au sein de la population adulte de la C.-B.

MÉTHODOLOGIE : Les chercheurs ont mené une étude rétrospective d'un an à l'égard de tous les patients qui se sont présentés au Vancouver General Hospital à cause d'une MII aiguë entre le $1^{\text {er }}$ janvier et le 31 décembre 2006. Ils ont colligé les données relatives au sexe, à l'âge, à l'ethnie, au type de MII et à l'étendue de la maladie, aux complications et aux stratégies de prise en charge. Ils ont confirmé les données cliniques au moyen de rapports de pathologie et de radiologie.

RÉSULTATS : Les chercheurs ont recensé 186 cas de MII, soit $56 \%$ de cas de maladie de Crohn (MC), $43 \%$ de cas de colite ulcéreuse (CU) et $1 \%$ de cas de colite indéterminée. Le taux annuel de cas de MII exigeant une hospitalisation chez les Blancs correspondait à 12,9 cas pour 100000 personnes $(7,9$ cas pour 100000 personnes atteintes de MC et 5,0 cas pour 100000 personnes atteintes de CU). Ce taux se comparait au taux annuel de MII chez les Asiatiques du Sud, qui correspondait à 7,7 cas pour 100000 personnes $(1,0$ cas pour 100000 personnes atteintes de $\mathrm{MC}$ et 6,8 cas pour 100000 personnes atteintes de $\mathrm{CU}$ ) et, chez les Asiatiques du Pacifique, à 2,1 cas pour 100000 personnes $(1,3$ cas pour 100000 personnes atteintes de $\mathrm{MC}$ et 0,8 cas pour 100000 personnes atteintes de CU). Le ratio hommes-femmes était plus élevé chez les Asiatiques du Sud et les Asiatiques du Pacifique que chez les Blancs. L'étendue de la maladie de même que les complications étaient considérablement différentes selon les groupes raciaux.

CONCLUSIONS : Ces résultats préliminaires laissent supposer qu'il existe des disparités ethniques dans les taux annuels de MII exigeant une hospitalisation au sein de la population adulte de la C.-B. Le taux de MC était considérablement plus élevé au sein de la population blanche que des populations d'Asie du Sud et d'Asie du Pacifique. La population d'Asle du Sud présentait un taux plus élevé de CU, de complications et de personnes de sexe masculin. Fait intéressant, le taux de MC et de CU le moins élevé s'observait au sein de la population d'Asiatiques du Pacifique. Ces différences raciales, qui étaient statistiquement significatives, laissent croire que l'ethnodiversité et les changements environnementaux jouent un rôle dans la prévalence des MII à Vancouver.

suggested that genetic susceptibility, environmental triggers and a dysfunctional host immune response all play a role in the expression of IBD and its subtypes ulcerative colitis (UC) and Crohn's disease (CD) (5).

Epidemiological studies can help to elucidate the interaction between genetic and environmental factors that manifest as a specific disorder. The study of migrant populations provides a unique opportunity

nflammatory bowel disease (IBD) is a chronic disorder of the intes-
tinal tract that affects almost 0.5\% of Canadians (1). It has signifi-
cant worldwide geographical variation, with North America and
Northern Europe reporting the highest prevalence rates (2), whereas
studies of eastern European and Asian populations describe much
lower rates $(3,4)$. Although its precise etiology is unknown, it has been

${ }^{1}$ Department of Medicine, University of British Columbia; ${ }^{2}$ Department of Medical Statistics, BC Cancer Agency, Vancouver, British Columbia

Correspondence and reprints: Dr Baljinder Salh, 5th Floor, 2775 Laurel Street, Vancouver, British Columbia V5Z 1M9.

Telephone 604-875-5287, fax 604-875-5447, e-mail bsalh@interchange.ubc.ca

Received for publication June 4, 2010. Accepted August 31, 2010 
to examine the associations of similar lifestyles and different gene pools and the correlation with disease rates. Adult South Asian migrants in the United Kingdom (UK) were shown to have higher rates of UC than the native European population (6). In addition, it was reported that second-generation migrants have increased rates of IBD, as shown in adult South Asian patients in the UK (7) and in pediatric South Asian patients in Vancouver, British Columbia (BC) (8) compared with the indigenous Caucasian population. Pacific Asian countries have historically reported some of the lowest rates of IBD in the world (4). However, relatively recent studies (9) suggest that the rates of IBD are increasing in the Asian Pacific region.

Understanding the epidemiology of IBD in areas of ethnic diversity may play a key role in understanding its etiology. Vancouver, with its migrating populations and changing demographics, offers a unique opportunity to examine the role of ethnicity in the prevalence, expression and severity of IBD and its subtypes.

\section{METHODS}

\section{Population}

In 2006, the population of metropolitan Vancouver was 2,097,965. The total visible minority population accounted for 875,300 (42\%). According to the Employment Equity Act (Department of Justice, Canada [www.justice.gc.ca]), visible minorities are defined as "persons, other than Aboriginal, who are non-Caucasian in race or non-white in color". The majority population (Caucasians) accounted for 1,222,665 (58\%). Of the total visible minority population, South Asians accounted for 207,160 (10\%), Pacific Asians for 451,790 (22\%) and others for 216,445 (10\%). The 'South Asian' population was defined as individuals of East Indian, Pakistani or Sri Lankan descent. 'Pacific Asians' encompassed individuals of Chinese, Japanese or Korean descent. The 'other' population encompassed individuals of black, Filipino, South American or Southeast Asian descent (10).

\section{Case identification}

A single-centre, retrospective, cross-sectional analysis was undertaken with data collected from medical charts of all IBD patients presenting acutely to Vancouver General Hospital (VGH) - the largest quaternary hospital in BC - between January 1, 2006, and December 31, 2006, and requiring hospitalization. Data were extracted from the electronic medical records systems of Vancouver Coastal Health: Quality Utilization Information Support Team and Patient Care Information System. Data collected included patient age, sex, ethnicity, length of hospital stay, disease type, disease extent, complications and management.

The diagnoses of IBD and its subtypes UC and CD were confirmed through clinical, endoscopic, pathological and radiological evaluation. $\mathrm{CD}$ was defined as the presence of discontinuous lesions, aphthous ulcers and 'cobblestoning' on endoscopy. Histological evidence of CD encompassed focal ulcerations and acute and chronic inflammation. Radiological evidence included strictures, perforations or fistulas. UC endoscopy findings comprised continuous lesions, superficial lesions, proximal extension from rectum, loss of vascular markings, areas of spontaneous bleeding and evidence of backwash ileitis. Histological evidence of UC included crypt abscesses and gland atrophy. Indeterminate colitis (IC) was diagnosed when disease type was unclear after complete evaluation with endoscopy and histological examination of biopsies. Other subtypes of colitis including infectious, ischemic, collagenous and lymphocytic were excluded.

Disease extent was defined using the following terms: UC was described as proctitis, left-sided colitis, pancolitis or fulminant colitis. Proctitis denoted disease limited to the rectum; left-sided colitis referred to disease extending from the sigmoid colon to the splenic flexure; pancolitis described disease beyond the splenic flexure, extending to the cecum; fulminant colitis referred to extensive colonic involvement, often pancolitis, in addition to a severe clinical presentation. For CD, disease extent was described by small bowel involvement only, ileocolitis and colitis. Ileocolitis referred to involvement of the ileum and colon. Colitis referred to disease limited to the colon.

Complications due to IBD were separated into intestinal and extraintestinal. Disease management was categorized as either medical or surgical.

\section{Statistical methods}

Figures for the population of metropolitan Vancouver, stratified according to ethnicity, were obtained from Statistics Canada Census 2006, 'Highlight tables, Ethnocultural Portrait of Canada' (www. statcan.gc.ca). Annual rates were calculated per 100,000 person years because admissions to VGH do not indicate the patient's ethnicity, which would have provided the denominator. It should be recognized that the rates generated were underestimates of the true hospitalization rates for these disorders across metropolitan Vancouver because the relevant information from other main (but smaller) hospitals was not available. Descriptive statistics were generated and 95\% CIs were calculated. Comparisons were made using $\chi^{2}$ or Fisher's exact tests, and $z$ test for population statistics and one-way ANOVA. The alpha level of significance (ie, P) for a two-sided test was set at 0.05. The statistical analyses were performed using SAS version 9.1 (SAS Institute, USA) for Windows (Microsoft Corporation, USA).

\section{Ethics}

Ethics approval for the present study was obtained from the University of British Columbia Clinical Research Ethics Board and the Vancouver Coastal Health Authority.

\section{RESULTS}

A total of 185 cases of IBD - 103 cases of CD (56\%), 80 cases of UC $(43 \%)$ and two cases of IC (1\%) - were evaluated in the present study (Table 1).

The Caucasian population accounted for $86 \%$ of IBD cases, South Asians accounted for $8.6 \%$, Pacific Asians accounted for $4.3 \%$ and other populations accounted for $1 \%$. Ninety-five Caucasian patients (60\%) were diagnosed with CD, 62 (39\%) with UC and two (1\%) with IC. Pacific Asians had a similar distribution of disease type, with five patients $(62.5 \%)$ diagnosed with $\mathrm{CD}$, three $(37.5 \%)$ diagnosed with UC and none diagnosed with IC. In contrast, two South Asian patients $(12 \%)$ were diagnosed with CD and 14 (88\%) were diagnosed with UC. South Asians were observed to have a greater than twofold increase in the likelihood of being diagnosed with UC than Caucasians or Pacific Asians.

The annual hospitalization rate for IBD in the metropolitan Vancouver population was 9.4 per 100,000 person years (Figure 1). Compared with the metropolitan Vancouver population demography, Caucasians had a significantly higher rate (13.0 per 100,000 person years) $(\mathrm{P}<0.05)$ and Pacific Asians had a significantly lower rate $(2.1$ per 100,000 person years) $(P<0.05)$. For Caucasians, the annual rates of $C D$ and UC were 7.8 per 100,000 person years and 5.1 per 100,000 person years, respectively. For South Asians, the annual rates of CD and UC were 1.0 per 100,000 person years and 6.8 per 100,000 person years, respectively. For Pacific Asians, the annual rates of $\mathrm{CD}$ and $\mathrm{UC}$ were 1.3 per 100,000 person years and 0.8 per 100,000 person years, respectively.

Caucasians had significantly higher rates of IBD and CD than the other ethnic populations $(\mathrm{P}<0.05)$. With respect to $\mathrm{UC}$, both Caucasians and South Asians had significantly higher rates than the rest of the ethnic populations $(\mathrm{P}<0.05)$. Pacific Asians had consistently demonstrated low rates of IBD, CD and UC compared with all other ethnic groups $(\mathrm{P}<0.05)$ (Figure 2).

The median length of hospital stay for IBD, CD and UC patients was six, five and six days, respectively There was no significant difference in length of hospital stay among the different ethnic populations for IBD ( $\mathrm{P}=0.5065$ [one-way ANOVA] $), \mathrm{CD}(\mathrm{P}=0.6698$ [one-way ANOVA] $)$ and UC (P=0.8040 [one-way ANOVA]). 
TABLE 1

Ethnicity, sex, and age of adult inflammatory bowel disease patients

\begin{tabular}{|c|c|c|c|c|}
\hline & \multirow[b]{2}{*}{$\begin{array}{c}\text { Population } \\
(n=185)\end{array}$} & \multicolumn{3}{|c|}{ Disease subtype } \\
\hline & & $\begin{array}{c}C D \\
(n=103)\end{array}$ & $\begin{array}{c}\text { UC } \\
(n=80)\end{array}$ & $\begin{array}{c}\text { IC } \\
(n=2)\end{array}$ \\
\hline \multicolumn{5}{|l|}{ Ethnicity, $\mathrm{n}$} \\
\hline Caucasian & 159 & 95 & 62 & 2 \\
\hline South Asian & 16 & 2 & 14 & 0 \\
\hline Pacific Asian & 8 & 5 & 3 & 0 \\
\hline Other & 2 & 1 & 1 & 0 \\
\hline \multicolumn{5}{|c|}{ Sex, n (male/female) } \\
\hline Vancouver (BC) & $110 / 75$ & $58 / 50$ & $50 / 30$ & $2 / 0$ \\
\hline Caucasian & $91 / 68$ & $50 / 40$ & $39 / 23$ & $2 / 0$ \\
\hline South Asian & $11 / 5$ & $2 / 0$ & $9 / 5$ & $0 / 0$ \\
\hline Pacific Asian & $7 / 1$ & $5 / 0$ & $2 / 1$ & $0 / 0$ \\
\hline Other & $1 / 1$ & $1 / 0$ & $0 / 1$ & $0 / 0$ \\
\hline \multicolumn{5}{|l|}{ Age, years (mean) } \\
\hline Vancouver & 39.4 & 47.7 & 37.9 & \\
\hline Caucasian & 40.2 & 41.3 & 38.6 & \\
\hline South Asian & 33.3 & 25 & 34.5 & \\
\hline Pacific Asian & 35.1 & 37.4 & 31.3 & \\
\hline Other & 42.5 & 27 & 58 & \\
\hline \multicolumn{5}{|c|}{ Age, years (median) } \\
\hline Vancouver & 39 & 42 & 35 & \\
\hline Caucasian & 39 & 42 & 35 & \\
\hline South Asian & 32.5 & 25 & 34 & \\
\hline Pacific Asian & 41 & 41 & 29 & \\
\hline Other & 42.5 & 27 & 58 & \\
\hline
\end{tabular}

$B C$ British Columbia; CD Crohn's disease; IC Indeterminate colitis; UC Ulcerative colitis

The median age at presentation for IBD, CD and UC patients was 39, 42 and 35 years, respectively. There was no significant difference in age at presentation among the different ethnic populations for IBD $(\mathrm{P}=0.1549$ [one-way ANOVA] $), \mathrm{CD}(\mathrm{P}=0.1683$ [one-way ANOVA] $)$ and UC $(\mathrm{P}=0.2611$ [one-way ANOVA] $)$.

A male predominance was observed in the South Asian and Pacific Asian population for $\mathrm{CD}$, with a higher male to female ratio than in the Caucasian population (2:0 and 5:0 versus $1.1: 1$, respectively; $\mathrm{P}=0.0470$ [Fisher's exact test]). With respect to disease type, South Asians were more likely to have UC than other populations $(\mathrm{P}=0.007$ [Fisher's exact test]). Analysis of UC disease extent revealed that South Asians had more extensive disease, with 50\% (seven of 14) of patients with pancolitis compared with 13\% (eight of 62) of Caucasian patients and 33\% (one of three) of Pacific Asian patients $(\mathrm{P}<0.001$ [Fisher's exact test]) (Figures 3 and 4$)$.

Of all IBD patients, $63 \%$ were medically managed, $35 \%$ were surgically managed and $2 \%$ had no information regarding treatment. There was no association between management type and ethnicity.

\section{DISCUSSION}

To our knowledge, the present study was the first to detail the crosssectional annual hospitalization rates of IBD, CD and UC among ethnic populations in Vancouver, BC. We found significant disparities in the rates of IBD, UC and CD between Caucasians and other ethnic populations. The annual rate of IBD warranting hospitalization in the metropolitan Vancouver population was 9.4 per 100,000 person years. While not a true incidence rate, this rate is a marker that described the burden of disease among the subset of the population with the most severe disease. The incidence of IBD in North America ranges from 6.2 per 100,000 person years to 28.9 per 100,000 person years (2).

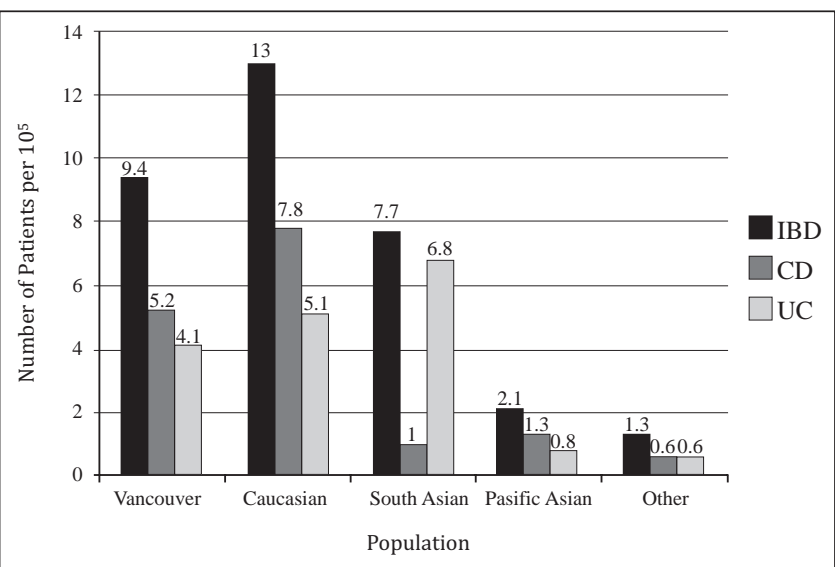

Figure 1) Annual hospitalization rates of inflammatory bowel disease (IBD), Crohn's disease (CD) and ulcerative colitis (UC) in hospitalized patients in Vancouver, British Columbia, in 2006

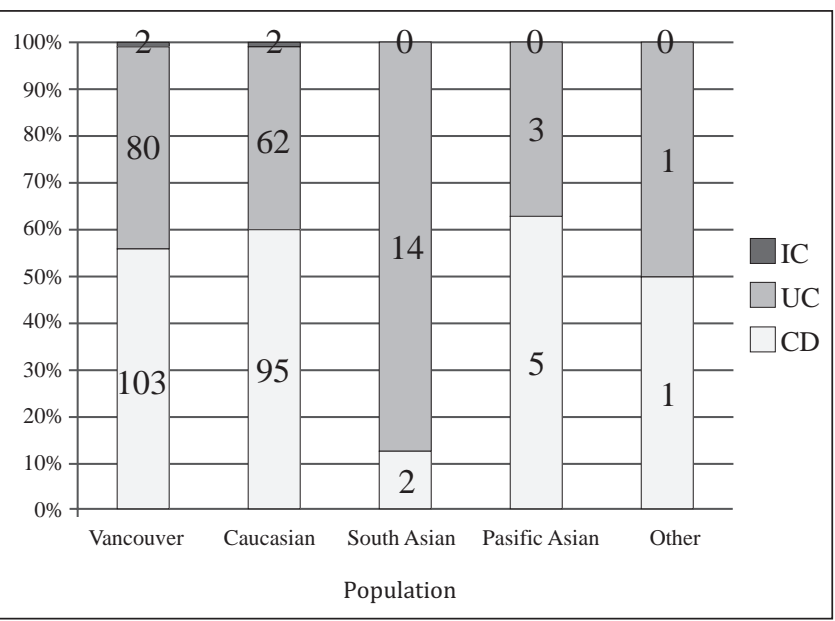

Figure 2) Disease type stratified according to ethnicity in inflammatory bowel disease patients. CD Crohn's disease; IC Indeterminate colitis; UC Ulcerative colitis

The migrant South Asian population in Vancouver had a higher rate of UC (6.8 per 100,000 person years) than the metropolitan Vancouver population (4.1 per 100,000 person years). Similarly, data from the UK (6) has shown a significantly higher incidence rate of UC in migrant South Asians than in the European population. In contrast, our data described the rate of $\mathrm{CD}$ in South Asians as much lower (1.0 per 100,000 person years) than in the Caucasian population (5.2 per 100,000 person years) of metropolitan Vancouver, which is also consistent with trends from Leicestershire, UK (7). There have been few reliable studies describing the incidence of $\mathrm{UC}$ and $\mathrm{CD}$ in nonimmigrant indigenous South Asian populations (11). Anecdotal studies have described IBD in indigenous South Asian Indians as less prevalent and less severe in presentation. Given the increasing westernization of South Asia, Sood et al (11) described an incidence rate of UC in Punjabi Indians in 2006 that appeared to be approaching the rates of UC in Europe and North America.

Similar to previously published data, our study demonstrated that Pacific Asians consistently had the lowest annual rates of IBD, UC and CD compared with Caucasian and South Asian populations. Several published studies (12-15) have described the incidence rates of IBD in indigenous Pacific Asian populations. Studies from Japan and Korea (4) have been described as the most reliable in presenting the true disease burden of IBD in Pacific Asians. Access to health care and diagnostic facilities, low rates of infectious colitis and a high degree of genetic and ethnic homogeneity in Japan and Korea are factors that 


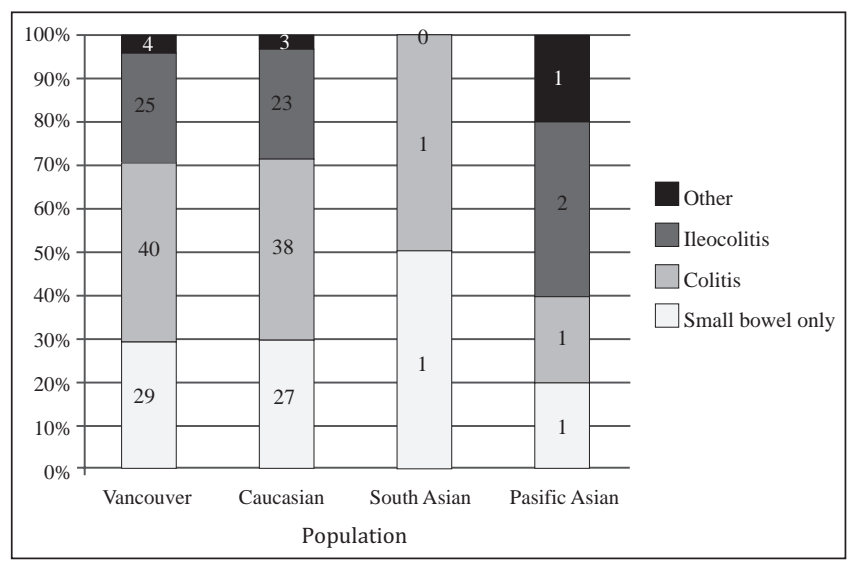

Figure 3) Disease extent stratified according to ethnicity for adult patients with Crohn's disease

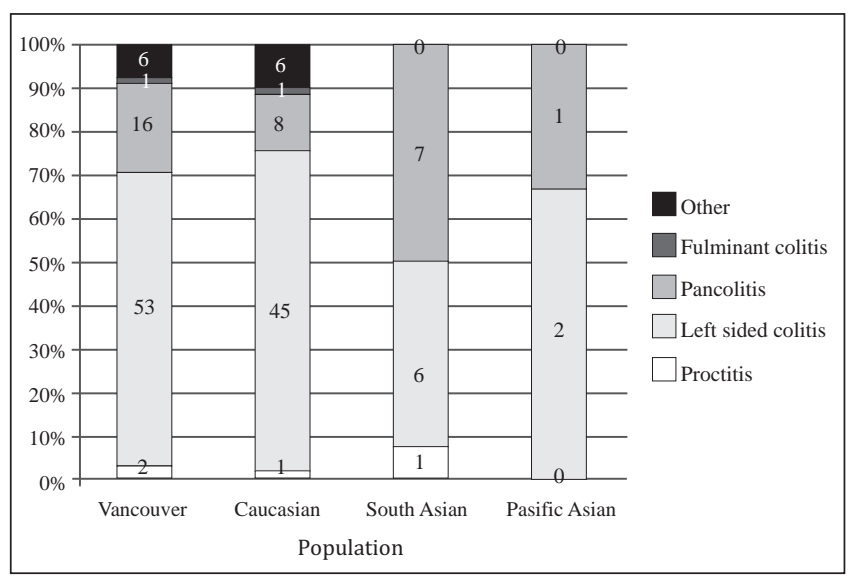

Figure 4) Disease extent stratified according to ethnicity for adult patients with ulcerative colitis

contribute to the reliability of these studies. A Japanese study (12) reported annual incidence rates of 1.95 per 100,000 person years for UC and 0.51 per 100,000 person years for CD in 1991. Our low annual rates of IBD in Pacific Asians is further validated by a parallel project conducted by our group (Table 2) that investigated annual rates of ischemic colitis in the same population warranting hospitalization. Ischemic colitis has a clinical presentation that is similar to that of an acute exacerbation of IBD and serves as a control population to minimize the effects of selection bias. Results from the present project suggest that the highest annual rates of ischemic colitis occur in Pacific Asians (1.8 per 100,000 persons years) compared with Caucasians (0.9 per 100,000 person years), South Asians (0.48 per 100,000 person years) and the global metropolitan Vancouver population ( 1.0 per 100,000 person years). This observation is important because it serves to underscore the fact that the Pacific Asian group was not under-represented in the IBD estimations through any lack of access to the VGH.

Our study showed two different trends among migrant populations of Vancouver. Compared with the indigenous Caucasian population, migrant South Asians have similar rates of IBD and, for UC, have higher rates. In stark contrast, migrant Pacific Asians have significantly lower rates of IBD, UC and CD than Caucasians.

The reasons for high rates of UC in migrant South Asian populations and low rates of IBD in migrant Pacific Asians are unclear. It has been proposed (2) that there are genetic, environmental, immunological, dietary and smoking-related factors that contribute to the expression of IBD. Of the many factors that influence the expression of IBD, two are particularly important - an inherent genetic predisposition dictated by
TABLE 2

Annual rates of ischemic colitis (IC) in hospitalized patients in 2006. Populations: Metropolitan (Metro) Vancouver (BC), Caucasian, South Asian, Pacific Asian and Other

\begin{tabular}{lccccc}
\hline IC & $\begin{array}{c}\text { Metro } \\
\text { Vancouver }\end{array}$ & Caucasian & $\begin{array}{c}\text { South } \\
\text { Asian }\end{array}$ & $\begin{array}{c}\text { Pacific } \\
\text { Asian }\end{array}$ & Other \\
\hline Population & $2,097,965$ & $1,222,665$ & 207,165 & 451,790 & 216,445 \\
IC, $\mathrm{n}$ & 20 & 11 & 1 & 8 & 0 \\
IC* & 1.0 & 0.9 & 0.48 & 1.8 & 0 \\
$95 \% \mathrm{Cl}$ & 0.53 to 1.36 & 0.36 to 1.41 & -0.46 to 1.43 & 0.46 to 2.55 & - \\
\hline
\end{tabular}

*Per 100,000 person years. BC British Columbia

ethnicity, and the influence of a 'western' environment. First, disparate predisposition to developing IBD may be due, in part, to the inherent genetic differences between South Asian and Pacific Asian populations. Studies of the indigenous Japanese population (12) reported an annual UC incidence rate of 1.95 per 100,000 person years in 1991. In contrast, Sood et al (11) described an incidence rate in indigenous Punjabi South Asians of 6.02 per 100,000 person years in 2003. Thus, the higher rates of IBD that we observed in South Asians compared with Pacific Asians in Vancouver may be a consequence of their higher baseline risk of developing IBD. Second, many studies have associated higher incidence rates of IBD with westernization and urbanization (7). A recent study by Pinsk et al (8) described a significantly higher incidence of IBD in the South Asian pediatric population compared with the $\mathrm{BC}$ pediatric population. They suggested that it reflected the effect of environment and lifestyle change on disease expression given that the vast majority of patients were second-generation immigrants. In addition, the hygiene hypothesis has been proposed to explain the high rates of IBD in western countries where exposure to infectious agents is low and sanitation is high (2). The degree and influence of western lifestyle is important in this equation, and should be studied further. For example, some populations may continue to live and work in closeknit communities and maintain a traditional diet despite living in a westernized environment, while others may fully immerse themselves in their new culture.

Importantly, our cross-sectional analysis likely captured the populations in the present study at different stages in their expression of IBD. It would be important to observe temporal trends of the incidence of IBD in migrant populations to further elucidate the factors that affect IBD expression.

\section{SUMMARY}

Our study demonstrated disparities in the annual rates of IBD among various ethnic populations in metropolitan Vancouver. South Asians had high rates of UC, whereas Pacific Asians had low rates of UC and CD. With respect to UC disease extent, South Asians had more extensive disease than any other population. These ethnic differences in annual rates highlight the effect of genetic predisposition and potential environmental factors on the expression of IBD. Further studies investigating the temporal patterns in incidence rates among different populations are needed to better understand the expression of IBD.

\section{REFERENCES}

1. Bernstein CN, Wajda A, Sevson LW, et al. The epidemiology of inflammatory bowel disease in Canada: A population-based study. Am J Gastroenterology 2006;102:1077-83.

2. Loftus EV. Clinical epidemiology of inflammatory bowel disease: Incidence, prevalence, and environmental influences. Gastroenterology 2004;126:1504-17.

3. Yang SK, Loftus EV Jr, Sandborn WJ. Epidemiology of inflammatory bowel disease in Asia. Inflamm Bowel Dis 2001;7:260-70.

4. Whelan G. Epidemiology of inflammatory bowel disease. Med Clin North Am 1990;74:1-12. 
5. Podolsky DK. Inflammatory bowel disease. N Engl J Med 2002;347:417-29.

6. Probert CS, Jayanthi V, Pinder D, et al. Epidemiological study of ulcerative proctocolitis in Indian migrants and the indigenous population of Leicestershire. Gut 1992;33:687-93.

7. Carr I, Mayberry JF. The effects of migration on ulcerative colitis: A three-year prospective study among Europeans and first- and second-generation South Asians in Leicester (1991-1994). Am J Gastroenterology 1999;94:2918-22.

8. Pinsk V, Lemberg DA, Grewal K, et al. Inflammatory bowel disease in the South Asian pediatric population of British Columbia. Am J Gastroenterology 2007;102:1077-83.

9. Ouyang Q, Tandon R, Goh KL, et al. The emergence of inflammatory bowel disease in Asian Pacific region. Curr Opin Gastroenterol 2005;21:408-13.

10. Statistics Canada, 2007. Vancouver, British Columbia (table). Community Profiles. 2006 Census. Statistics Canada Ottawa.
$<$ http://www12.statcan.ca/english/census06/data/profiles/community/ Index.cfm?Lang=E $>$ (Accessed on November 24, 2008).

11. Sood A, Midha V, Sood N, et al. Incidence and prevalence of ulcerative colitis in Punjabi, North India. Gut 2003;52:1587-90.

12. Morita N, Toki S, Hirohashi T, et al. Incidence and prevalence of inflammatory bowel disease in Japan: Nationwide epidemiological survey during the year 1991. J Gastroenterol 1995;30(Suppl 8):1-4.

13. Yoshida Y, Murata Y. Inflammatory bowel disease in Japan: Studies of epidemiology and etipathogenesis. Med Clin North Am 1990;74:67-90.

14. Yang S-K, Hong W-S, Min YI, et al. Incidence and prevalence of ulcerative colitis in the Songpa-Kangdong district, Seoul, Korea, 1986-1997. J Gastroenterol Hepatol 2000;15:1037-42.

15. Lai CL,Wu PC, Wong KL, et al. Clinical features of ulcerative proctocolitis in Hong Kong Chinese: A review of three decades. Am J Proctol Gastroenterol Colon Rectal Surg 1985;1:14-9. 


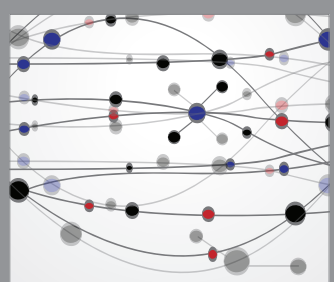

The Scientific World Journal
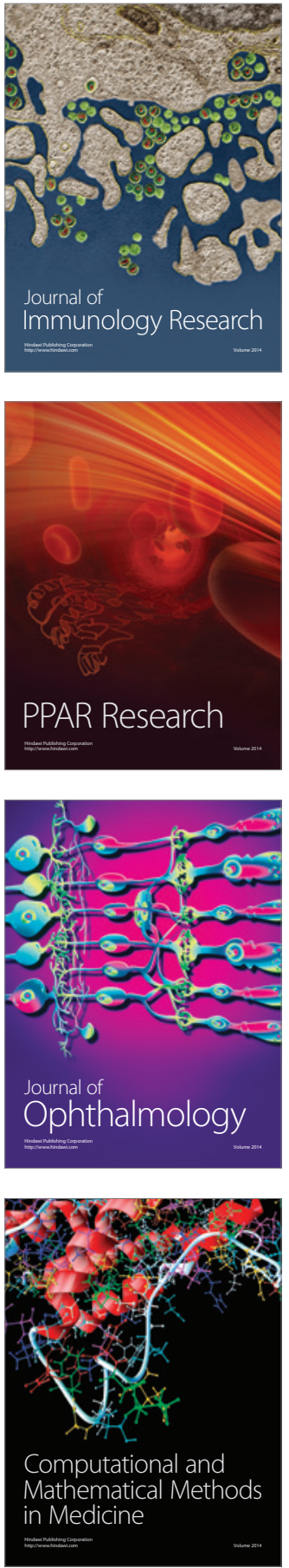

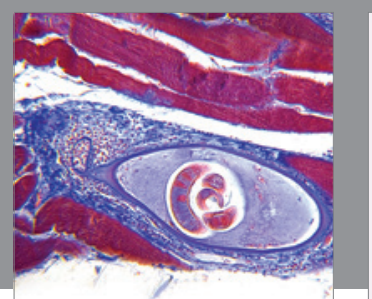

Gastroenterology Research and Practice

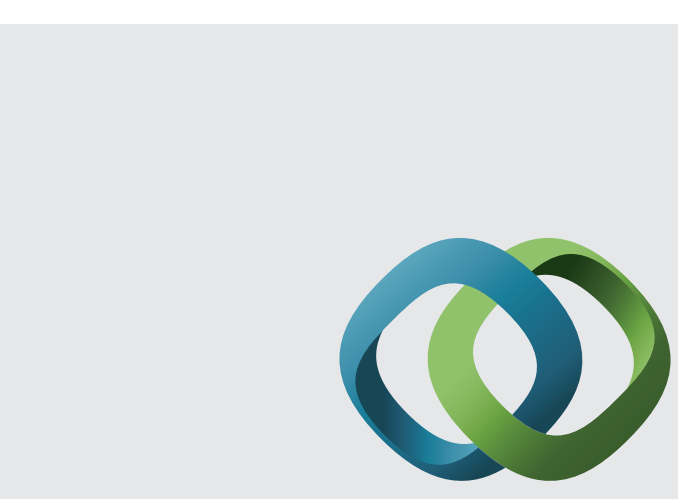

\section{Hindawi}

Submit your manuscripts at

http://www.hindawi.com
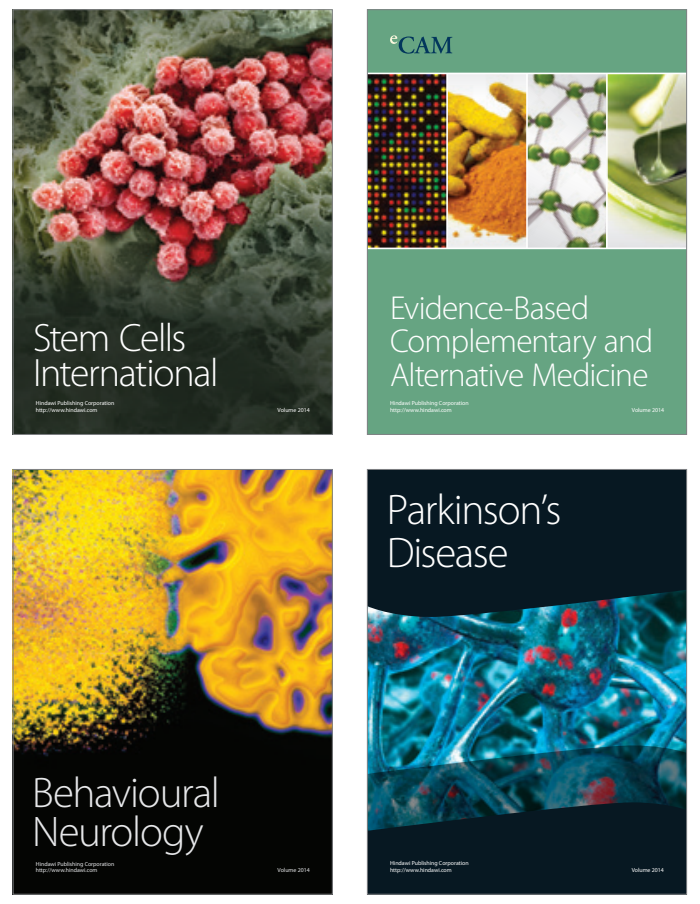
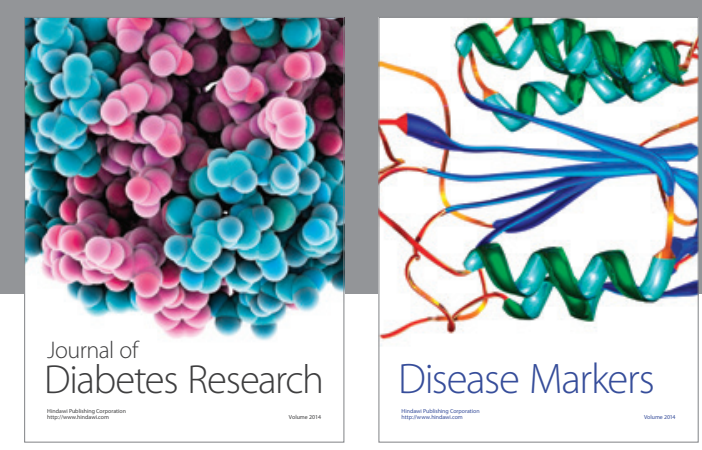

Disease Markers
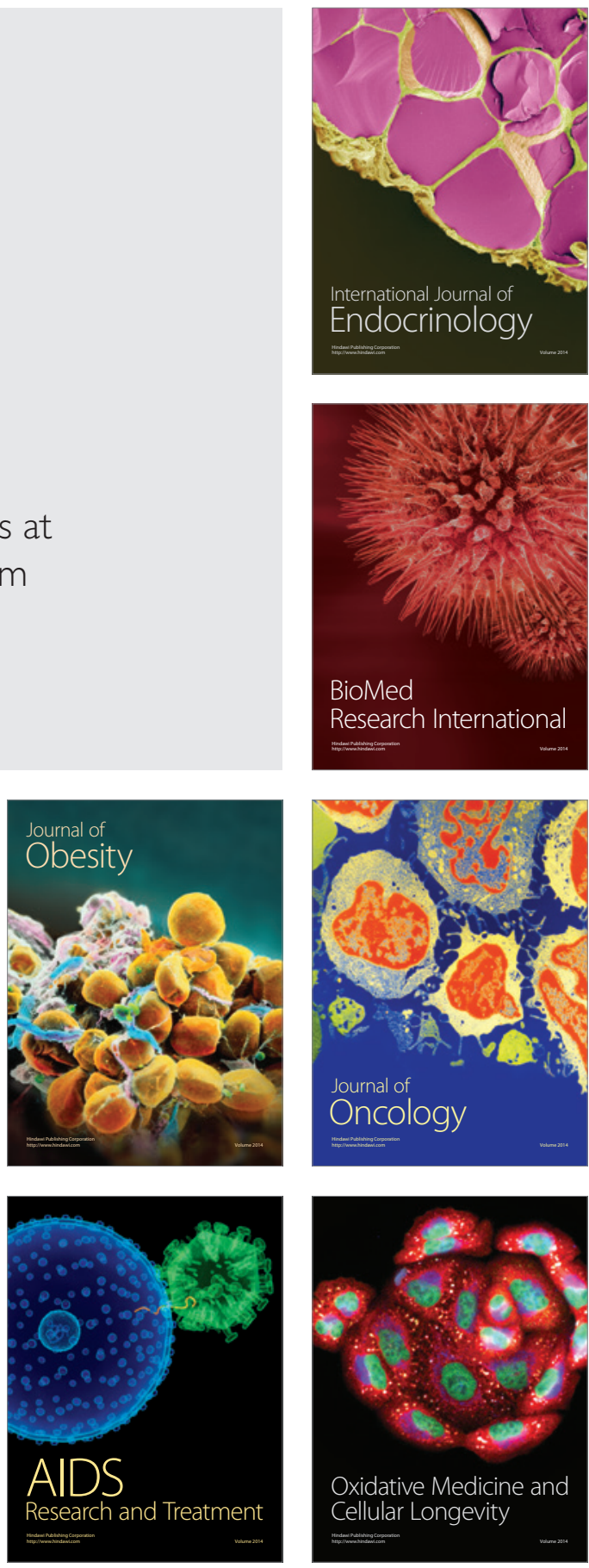